\title{
Model Reference Adaptive System for the Online Rotor Resistance Estimation in the Slip-Ring Machine Based Test-bench
}

\author{
Tamás Égető1*, Balázs Farkas² \\ ${ }^{1}$ Department of Electric Power Engineering, Faculty of Electrical Engineering and Informatics, \\ Budapest University of Technology and Economics, H-1521 Budapest, P.O.B. 91, Hungary \\ *Corresponding author, email: egeto.tamas@vet.bme.hu
}

Received: 06 May 2018, Accepted: 29 May 2018, Published online: 26 June 2018

\begin{abstract}
Motor control algorithms with high dynamics are generally based on two basic approach field oriented control (FOC) and direct torque control (DTC). The idea of the first one is to decompose the stator current based on the rotor flux, the second one controls the torque based on the stator flux. Therefore, the FOC is very sensitive to the parameter accuracy regarding the drive performance. That is why it is crucial to verify the parameter identification in the real environment. On the other hand, the parameter sensitivity of DTC is much smaller since the stator flux estimation requires only the knowledge of the stator resistance. The article focuses on the verification of rotor resistance identification in the FOC based drive system by means of the slip ring machine based test bench. The recommended procedure calculates the torque based on the stator current and flux to implement model reference adaptive system for online rotor resistance estimation without signal injection.
\end{abstract}

Keywords

rotor resistance, FOC, verification, MRAS

\section{Introduction}

Nowadays, the vector control of the induction machines is implemented in two ways: field oriented control and direct torque control $[1,2]$. In case of the FOC (Fig. 1) the rotor flux has to be online calculated in order to decompose the stator current into $d$ and q parts, so the motor parameters are necessary. Since they are not constant during the operation they have to be monitored online if the goal is to achieve high dynamic motor control. In case of the DTC only stator flux has to be calculated for the torque control, it requires only the knowledge of the inverter output voltage, current, and the value of the stator resistance. It implies that the control algorithm is not sensitive to the motor parameters with the exception of the stator resistance [3]. The performance of the DTC is deteriorated at low motor speed where the voltage drop is prevailed by the stator resistance. Another disadvantage of DTC is the necessity of the inverter output voltage measurement. However, it can be estimated based on the DC link voltage and switching state of the inverter but the dead time can distort the output voltage.

There is always a machine model (MM) in the center of every FOC based control method which is the base point of the control proceedings $[4,5]$. MM is used to simulate the real machine and in order to have proper simulation which follows well the behavior of the real machine it is essential to have a MM with the correct parameters. If the parameters are incorrect the control progress will fail or, at least, will be not sufficient.

Security, stability and reliability are needed in case of industrial and automotive applications and this conditions require high accuracy in the aspect of the control methods and the used MM. An inaccurate MM will result in undesired waves in the current and torque signals which are completely wrong in case of automotive applications. The main purpose of the design is the creation of a drive which has the possible best efficiency with the possible less effort, to find the optimum point of the operation which is the best and the cheapest. Usually, this operation point has very narrow limits and if the machine must operate there having a very accurate MM is indispensable. The online monitoring is carried out in order to determine the losses, find the optimum operation point and it is done by using examination signals which may have influence on the system which is undesired. 


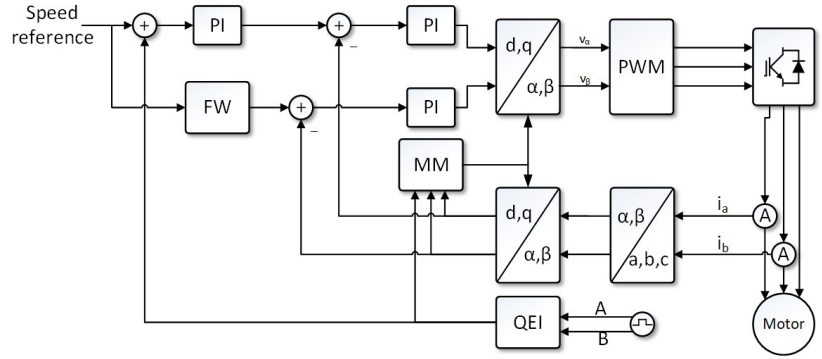

Fig. 1 FOC block diagram. QEI: Quadrature Encoder interface which evaluates the encoder signal, MM is the machine model which estimates the position and magnitude of the rotor flux, FW is the field weakening controller providing flux reference based on the speed reference.

All in all, the performance of FOC is ruled by the parameter estimation efficiency mainly by the rotor resistance. In case of the Squirrel Cage Rotor Induction Machine (SCIM) this resistance cannot be measured directly. It means that the verification of the specific FOC based drive can be done indirectly e.g. based on shaft torque measurement. In case of the Slip Ring Induction Machine (SRIM) direct online measurement is possible based on the rotor current sensor signal. The introduced estimation procedure is so advantageous because it does not require any injection of examination signals into the system since the SRIM lets measure the rotor properties.

The intent of this article is to show a method to estimate the rotor resistance based on the electromagnetic torque online. It is the aim to provide a process and a measurement environment that is suitable for measuring the rotor properties of a SRIM to create verification platform for the FOC based drives. To avoid the parameter sensitivity in the recommended solution the DTC approach is used in electromagnetic torque estimation.

\section{Role of the Rotor resistance estimation}

The possessing the correct value of the rotor resistance is very important to construct a MM. There are many online and offline solution for estimating the rotor resistance. The [6] and [7] uses the back-EMF for the parameter identification. The [8] shows an online solution to estimate the rotor resistance. There is another solution which uses the reactive power for the estimation of the rotor resistance [9]. An adaptive algorithm is shown in [10]. Kalman Filter can be also used to estimate the rotor resistance [11]. Most of these techniques requires signal injection by the inverter. Various methods can be seen in the comparative study in [12].

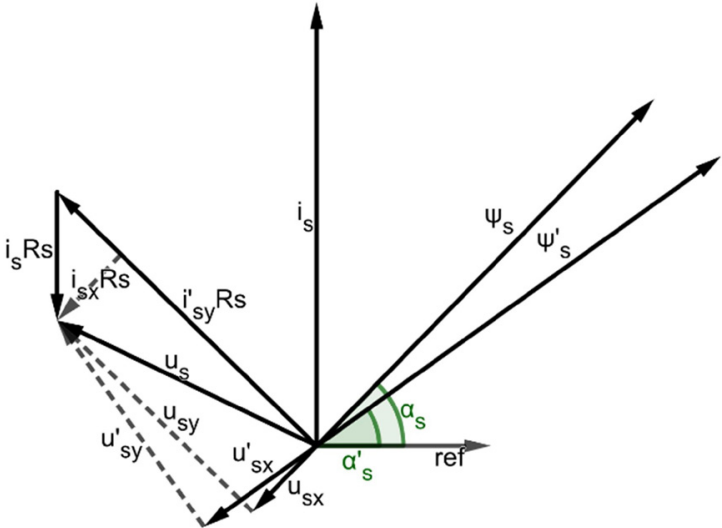

Fig. 2 Vector diagram to exemplify the effect of the inaccuracy in position of the stator flux on the stator voltage decomposition.

The measurement or the estimation of the rotor resistance in case of SCIM is not so simple because there can be more source for getting incorrect value which resulted in the bad positioning of the rotor flux. In the followings it is shown why it is recommended to use dynamic resistance value. The machine model is the basic part of the control process it is essential to possess proper parameters in order to satisfy the demands regarding the control. The dependency of the parameters of the machine model during development and verification must be taken into consideration.

Firstly, the most obvious phenomenon is the effect of the changing temperature on the resistance. As the higher the load on the motor goes, the higher the temperature of the coil will be. Thus, the resistance measured in "cold" state is not satisfied to use in the machine model. All in all, there should be used a proper rotor resistance for every single value of temperatures. The changing of the temperature dependent resistance is written by Eq. (1)

$R_{T}=R_{20}(1+\alpha \Delta T)$

The other critical point is the short circuit measurement which traditionally resulted the serial parameters of the equivalent circuit model. This resistance could be measured in high temperature because the short circuit causes high current, however, that resistance is not to be used in the machine model because in short circuit measurement the frequency of the rotor is much higher (about 50-100 times higher) than in the normal operation. The skin effect on higher frequencies modify the value of the resistance. Though, this effect is highly dependent on the physical structure of the electrical machines because e.g. the shaping of the slots is very important regarding the skin effect and the proximity effect. 


\section{Developed Algorithm}

The block diagram of the developed algorithm is shown on Fig. 3.

SRIMs are used traditionally to help to reduce high starter currents with connecting resistances into the rotor circuit through the slip rings. The stator has the common construction with a three phase windings and laminated iron core. The SRIM and SCIM stators are the same. The rotor has also a three phase windings which is short circuited via the slip rings. From the point of view measurement, the SRIM makes it possible to measure rotor current directly and because of the similarity with the SCIM it can be a good subject of the FOC based SCIM aimed drive verification.

Therefore, model reference adaptive system (MRAS) $[13,14]$ can be built to exploit the benefits of the SRIM. First of all, the SRIM makes it possible to measure the rotor current and based on that the electromagnetic torque can be estimated if the rotor resistance is known Eq. (3). On the other hand, the electromagnetic torque can be estimated based on the stator flux and stator current Eq. (5), if the stator resistance considered known and the iron loss is neglected which is a good approximation in the case the high-power motors. The second one can operate as a reference model in the torque calculation and the rotor resistance can be tuned in the first one $[15,16]$.

The current sensors in the rotor circuit measure the rotor current in the rotor oriented frame ('), it is transformed to the primary with taking into count the turn ratio (). However, it would not be needed from the point of view of MRAS, since the torque would be calculated based on the signals in rotor frame. Though, the FOC drive systems generally use the primary side quantities so the comparison between the tested FOC and the estimated rotor resistance by the MRAS is simpler in case of primary side transformed rotor resistance.

$$
\begin{aligned}
\bar{i}_{r S}^{\prime} & =a_{N} * \bar{i}_{r R} \\
M^{*} & =\frac{3}{\omega_{m e c h}} * p^{*} I_{r R}^{\prime 2} * R_{r e s t}^{\prime} * \frac{1}{s} \\
\overline{\Psi_{s S}} & =\int\left(\bar{U}_{s S}-\bar{i}_{s S}\right) d t \\
M_{r e f} & =\frac{3}{2} * p^{*} \bar{\Psi}_{s S} x{\overline{i_{s S}}} \\
& =\frac{3}{2} * p \int\left(\bar{U}_{s S}-\bar{i}_{s S}\right) d t x \bar{i}_{s S}
\end{aligned}
$$

Considering two different given cases for the torque calculation it is possible to create a PI controller to set the error between two estimations to zero. It actuates the rotor resistance value which is used in Eq. (3) in each iteration.

In this article two possible solutions are given to express the torque Eq. (3), Eq. (5): the PI controller uses the difference between these values to adjust the rotor resistance. The PI controller also behaves like a filter, it makes the estimation algorithm robust against the measurement noises.

If the estimated torque is smaller than the reference one the controller increase the rotor resistance. In the opposite case the controller reduces the estimated rotor resistance value. It is important that the value of the rotor resistance should be limited above zero and it cannot be negative. It is also needed to define an initial value of the resistance.

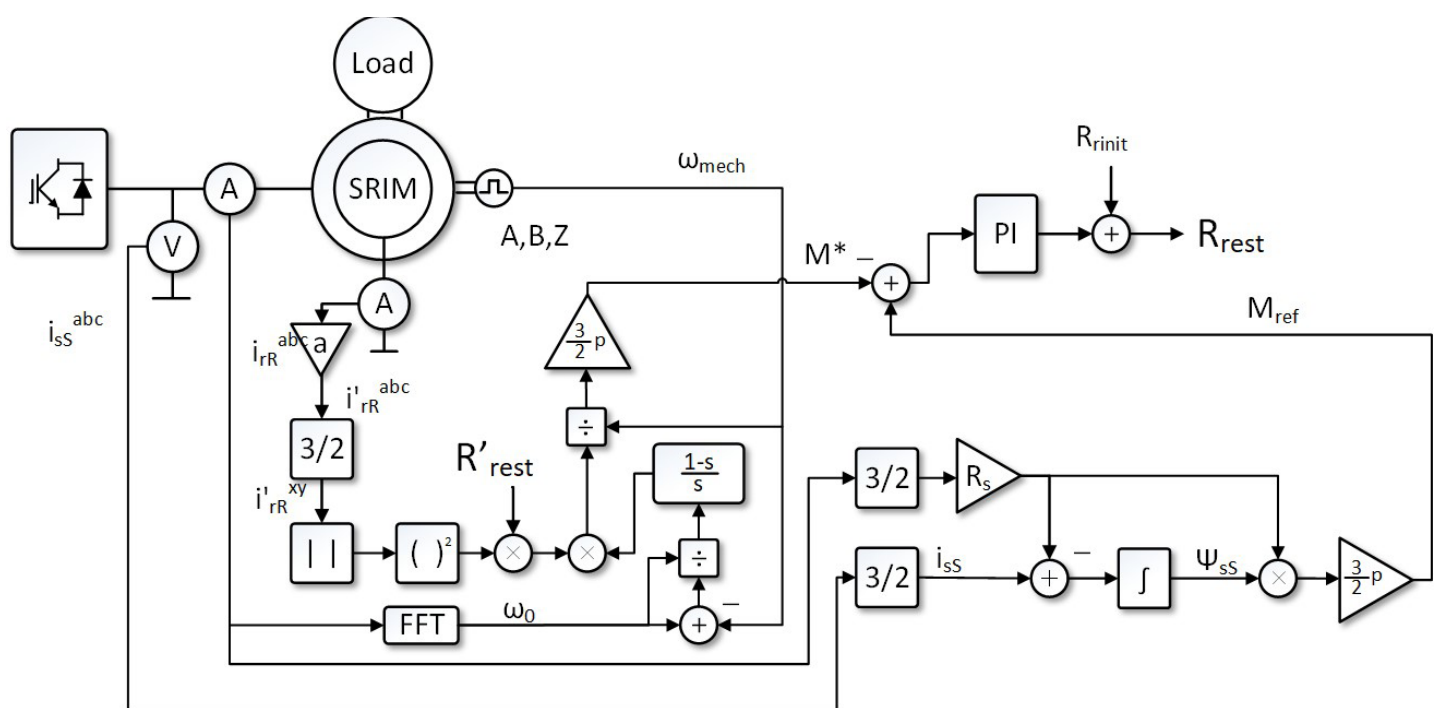

Fig. 3 Block diagram of the developed algorithm 


\section{Implementation of the Algorithm}

\subsection{Closed-loop Integrators}

According to Eq. (4) the stator flux linkage can be calculated by integration of the stator voltage considered the voltage drop at the stator resistance. Since the stator flux position is very sensitive to the drift in stator voltage measurement, the application of the open-loop integrators (Fig. 4) is not beneficial. The transient may cause DC offset in the flux estimation which strongly deteriorates the motor control operation. In addition, using the open - loop integrators at low frequencies should be avoided because of relative high voltage drop at stator resistance. To prevent the previously mentioned problems closed - loop integrators should be used. This kind of integrator can inherently compensate DC offset and drift (Fig. 5).

To prove this properties of the closed-loop integrator let's consider the following error in the stator flux linkage $[17,18]$ :

$\psi_{s}^{\prime}[n]=\psi_{s}[n]+\Delta \psi_{s}[n]$

The error is implied the error in the angle of the stator flux.

$\alpha_{s}^{\prime}[n-1]=\alpha_{s}[n-1]+\Delta \alpha_{s}[n-1]$

It causes the error in the voltage decomposition into the stator flux oriented frame.

$u_{s i}[n]=u_{s}[n]-i_{s}[n] * R_{s}$

$u_{s i d}^{\prime}[n]=u_{s i x}[n] * \cos \left(\alpha_{s}^{\prime}[n-1]\right)+u_{s i y}[n] * \sin \left(\alpha_{s}^{\prime}[n-1]\right)$

$u_{s i q}^{\prime}[n]=u_{s i y}[n] * \cos \left(\alpha_{s}^{\prime}[n-1]\right)-u_{s i x}[n] * \sin \left(\alpha_{s}^{\prime}[n-1]\right)$

$\omega_{s}^{\prime}[n]=\frac{u_{s i q}^{\prime}[n]}{\left|\psi_{s}\right|}=$

$\alpha_{s}^{\prime}[n]=\alpha_{s}^{\prime}[n-1]+\omega_{s}^{\prime}[n] * T_{s}$

if $\Delta \alpha_{s}[n-1]>0$ then $\Delta \omega_{s}[n]>0$ therefore $\omega_{s}^{\prime}[n]>\omega_{s}[n]$ so angle error reduced:

$\Delta \alpha_{s}[n]<\Delta \alpha_{s}[n-1]$

if the error in the angle of the stator flux is negative the situation is the same.

\subsection{Data Acquisition Concept}

The recommended rotor resistance measurement algorithm is based on the motor model. The initial conditions may

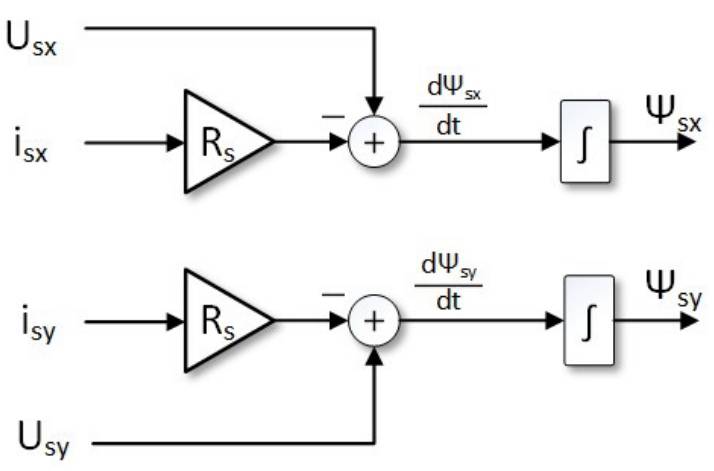

Fig. 4 Open-loop integrator based stator flux estimation

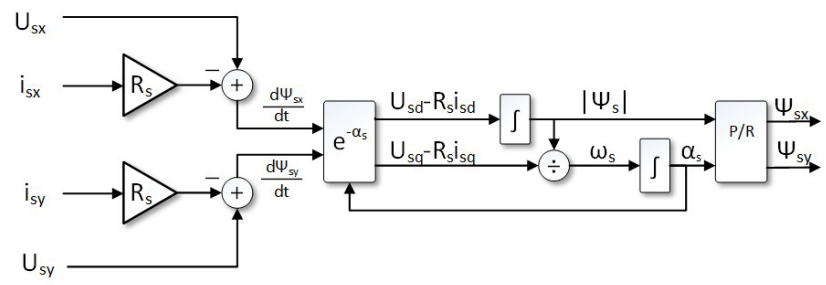

Fig. 5 Close-loop integrator for stator flux estimation, based on the decomposition to stator flux oriented frame.

influence significantly the dynamic of the measurement. The problem is that the algorithm starts after start trigger, thus, a transient is expectable during the measurement. In the future the dynamic can be enhanced by means of model initial condition adaptation to the actual state of system but in this article algorithm start with zero initial conditions. Another important aspect of the algorithm implementation is that model and power parts of the model are not real time synchronized, since currently algorithm does not use stream, so the signal post-processing based on the measurement log of the DAQ system. Although it is important to mention that the sampling of the different measurement channels should be real-time synchronized, the requirement for this synchronism depends on the dynamics of the investigated phenomenon. Currently the article focuses on the fundamental frequency related phenomena.

\section{Simulation}

The purpose of the simulation is to emulate the test bench operation. The signals of the current and voltage are logged for the signal post processing. The simulation of the power circuit is done by means of SimPower System toolbox. During the simulation the relevant current, voltage and speed signals are acquired by the Simulink "ToWorkspace" blocks, data acquisition period is 2 seconds and sampling time is 1 us. 
The SRIM test-bench in BME drive laboratory with $55 \mathrm{~kW}$ shaft power was chosen as a subject of the simulation. Previously, the motor parameters were identified by the traditional blocked-rotor and open-circuit measurement.

The SimPower system model was parametrized by these parameters except the iron loss resistance which was neglected. The initial value of the rotor resistance was 1 $\mathrm{m} \Omega$, which had got unrealistic high error. It is aimed to test the robustness of the proposed procedure against the error in the initial value of the rotor resistance.

$$
\begin{aligned}
& R_{s}=32 m \Omega, R_{r}^{\prime}=95.5 m \Omega, L_{s l}=340 \mu H, L_{r l}^{\prime}=340 \mu H \\
& L_{m}=12.3 m H, R_{\text {Iron }}=100 \Omega, n=1500 R P M, s \sim 1.5 \%
\end{aligned}
$$

The transient of the rotor resistance measurement can be seen on Fig. 6, the dashed line represents the real rotor resistance value. As it can be seen the settling time of the rotor resistance estimation is around 500 us. Based on Fig. 7 the static accuracy of the recommended estimation

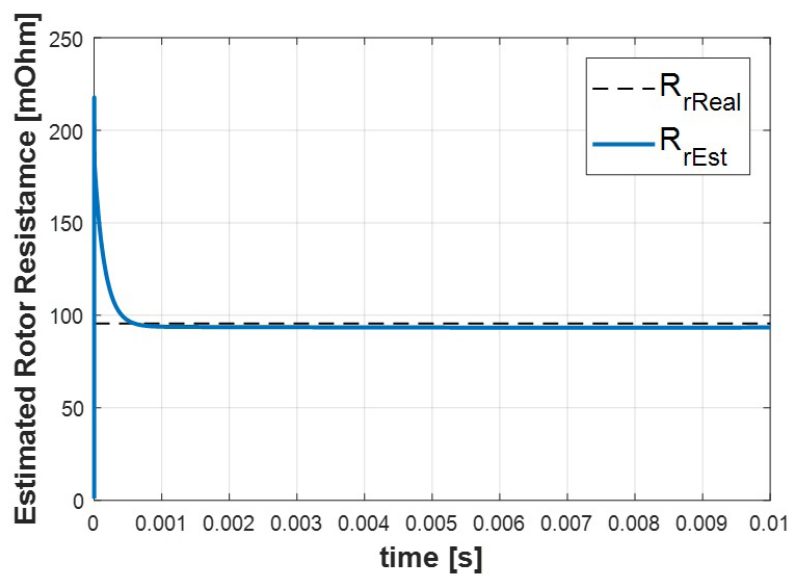

Fig. 6 Transient of the rotor resistance estimation over time

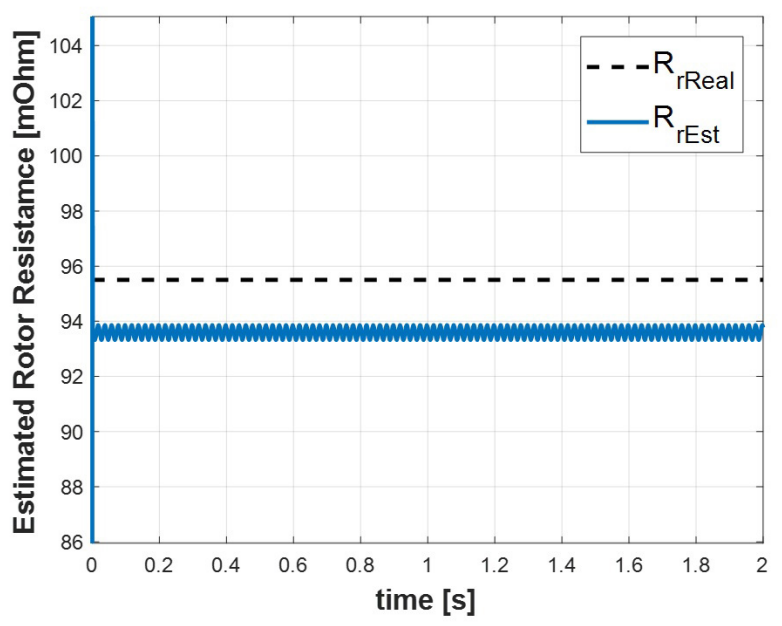

Fig. 7 Static accuracy of the rotor resistance estiamtion over time procedure can be evaluated, the error of the estimation is around $2 \mathrm{~m} \Omega$. This error is a consequence of the iron losses since the torque in the reference model includes the effect of the iron losses, this fact is the limitation of this method.

The space vector of the stator flux and stator current can be seen on Fig. 8. This figure also shows the space vector trajectory of the space vector over time. As it is expected the length of the stator flux space vector and stator current is constant, therefore the trajectory is circle and the angle between the space vector of the stator current and stator flux are also constant over time.

\section{Conclusion}

The article introduces an online rotor resistance estimation procedure for the SRIM based test bench. As it was mentioned the purpose of this algorithm to verify FOC based drive system parameter estimation performance over time without direct resistance measurement or signal injection.

The recommended algorithm is verified by means of the Matlab SimPower System simulation. According to simulation results the recommended procedure can estimate the rotor resistance value with accuracy of few percentage with very short settling time.

Future work is related to the proposed algorithm implementation and test in the BME drive laboratory on the SRIM based $55 \mathrm{~kW}$ test bench.

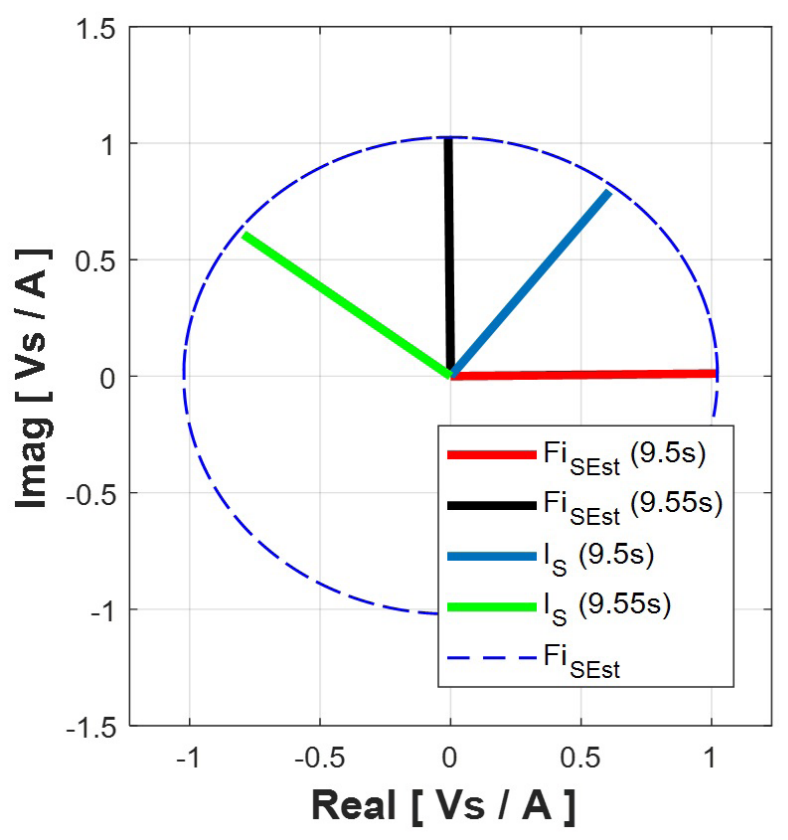

Fig. 8 Trajectory of current and flux space vectors in two different moment 


\section{Acknowledgement}

This work was performed in the frame of FIEK 16-1-20160007 project, implemented with the support provided from

\section{References}

[1] Rodriguez, J., Kennel, R. M., Espinoza, J. R., Trincado, M., Silva, C. A., Rojas, C. A. "High-Performance control strategies for electrical drives: An experimental assessment", IEEE Transactions on Industrial Electronics, 59(2), pp.812-820, 2012. https://doi.org/10.1109/TIE.2011.2158778

[2] Robyns, B., Sente, P. A., Buyse, H. A. "Influence of digital current control strategy on the sensitivity to electrical parameter uncertainties of induction motor indirect field-oriented control", IEEE Transactions on Power Electronics, 14(4), pp. 690-699, 1999. https://doi.org/10.1109/63.774206

[3] Del Pizzo, A., Pagano, E., Perfetto, A. "Comparative analysis and parameter sensitivity of field oriented speed controlled asynchronous motors", In: 1989 Fourth International Conference on Electrical Machines and Drives, London, UK, 1989, pp. 322-327.

[4] Chiasson, J. "Modeling and High-Performance Control of Electric Machines", Wiley-IEEE Press, Piscataway, NJ, USA, 2005.

[5] Rowan, T. M., Kerkman, R. J., Leggate, D. "A simple on line adaptation for indirect field oriented of an induction machine", IEEE Transaction on Industry Application, 27(4), pp. 720-727, 1991. https://doi.org/10.1109/28.85488

[6] Peng, F. Z., Fukao, T. "Robust speed identification for speedsensorless vector control of induction motors", IEEE Transactions on Industry Applications, 30(5), pp. 1234-1240, 1994. https://doi.org/10.1109/28.315234

[7] Rashed, M., Stronach, A. F. "A stable back-emf MRAS based sensorless low speed Induction motor drive insensitive to stator resistance variation", IEE Proceedings - Electric Power Applications, 151(6), pp. 685-693, 2004.

https://doi.org/10.1049/ip-epa:20040609

[8] Nait Said, M. S., Benbouzid, M. E. H. "Induction motors direct field oriented control with robust on-line tuning of rotor resistance", IEEE Transactions on Energy Conversion, 14(4), pp. 10381042, 1999.

https://doi.org/10.1109/60.815025

[9] Maiti, S., Chakraborty, C., Hori, Y., Ta, M. C. "Model reference adaptive controller-based rotor resistance and speed estimation techniques for vector controlled induction motor drive utilizing reactive power", IEEE Transactions on industrial Electronics, 55(2), pp. 594-601, 2008.

https://doi.org/10.1109/TIE.2007.911952 the National Research, Development and Innovation Fund of Hungary, financed under the FIEK 16 funding scheme.

[10] Kanwal, K., Singh, M. "Rotor Resistance Estimation for Induction Motor using Model Reference Adaptive Controller", In: 2016 IEEE 7th Power India International Conference (PIICON), Bikaner, India, 2016, pp. 1-6. https://doi.org/10.1109/POWERI.2016.8077326

[11] Talla, J., Peroutka, J., Blahnik, V., Streit, L. "Rotor and Stator Resistance Estimation of Induction Motor Based on Augmented EKF", In: 2015 International Conference on Applied Electronics (AE), Pilsen, Czech Republic, 2015, pp. 253-258.

[12] Kojabadi, H. M., Abarzadeh, M., Chang, L. "A Comparative Study of Various Methods of IM's Rotor Resistance Estimation", In: 2015 IEEE Energy Conversion Congress and Exposition (ECCE), Montreal, QC, Canada, 2015, pp. 2884-2891. https://doi.org/10.1109/ECCE.2015.7310064

[13] Villazana, S., Seijas, C., Caralli, A., Villanueva, C., Arteaga, F. "SVM-based and Calssical MRAS for On-line Rotor Resistance Estimation", In: 2007 IEEE International Symposium on Intelligent Signal Processing, Alcala de Henares, 2007, pp. 1-6. https://doi.org/10.1109/WISP.2007.4447592

[14] Cao, P., Zhang, X., Yang, S. "A Unified-Mode-Based Analysis of MRAS for Online Rotor Time Constant Estimation in an Induction Motor Drive", IEEE Transactions on Industrial Electronics, 64(6), pp. 4361-4371, 2017. https://doi.org/10.1109/TIE.2017.2668995

[15] Vajsz, T., Számel, L., Rácz, Gy. "A közvetlen nyomatékszabályozás elve, megvalósítása, és főbb tulajdonságai aszinkron motoros hajtások esetében", (The principle, realization and main features of direct torque control in the case of $\mathrm{AC}$ induction motor drives) In: In: ENELKO 2014 XV. Nemzetközi Energetika-Elektrotechnika konferencia, Odorheiu Secuiesc, Romania, 2014. (in Hungarian)

[16] Vajsz, T., Számel, L., Rácz, Gy. "Simulation, analysis and comparison of field-oriented control and direct torque control", In: 30th Kandó Conference, Budapest, Hungary, 2014, pp. 1-6.

[17] Bodlea, I., Nasar, S. A. "The Induction Machines Design Handbook", 2nd ed., CRC Press, Dec 2009

[18] Vas, P. "Sensorless Vector and Direct Torque Control", Oxford University Press, United Kingdom, 1998. 